Article

\title{
The Influences of Various Testing Conditions on the Evaluation of Household Biomass Pellet Fuel Combustion
}

\author{
Yixiang Zhang ${ }^{1,2,3}$, Zongxi Zhang ${ }^{1,2,3}$, Yuguang Zhou ${ }^{1,2,3, *}$ and Renjie Dong ${ }^{1,2,3}$ \\ 1 Bioenergy and Environment Science \& Technology, College of Engineering, China Agricultural University, \\ Beijing 100083, China; yinhezhixing2005@163.com (Y.Z.); jnzhangzongxi@163.com (Z.Z.); \\ rjdong@cau.edu.cn (R.D.) \\ 2 Key Laboratory of Clean Production and Utilization of Renewable Energy, Ministry of Agriculture and Rural \\ Affairs, Beijing 100083, China \\ 3 National Center for International Research of BioEnergy Science and Technology, Ministry of Science and \\ Technology, Beijing 100083, China \\ * Correspondence: zhouyg@cau.edu.cn; Tel.: +86-10-62737885
}

Received: 2 April 2018; Accepted: 1 May 2018; Published: 3 May 2018

\begin{abstract}
Direct combustion of solid biomass fuel is one of the most common energy sources in developing countries. Evaluation of technology for household biomass pellet fuel combustion is critical, since promoting poorly designed devices may have risks due to exposure to high levels of emissions. This study evaluated the effects of various testing conditions on a top-lit forced-up-draft semi-gasifier cooking stove. An orthogonal test was designed with different fuel masses, chamber heights, air supply rates, and ending points. The investigation showed that using forced secondary air and more fuel tended to improve both thermal and gas emissions performance. The ending points did not have significant effects on thermal efficiency or the carbon dioxide emission factor, but did affect particulate matter emission. A relatively lower chamber height demonstrated better performance on thermal metrics. However, a taller flame had better performance on particulate matter emission factors. The results of the indicators reported by different bases, such as fuel mass-based or useful energy-based were also quite different. The study showed that different testing conditions had significant effects on combustion performances. Testing sequences and emission factors should be reviewed and defined clearly when forming testing methods and standards for biomass pellet fuel combustion.
\end{abstract}

Keywords: biomass pellet fuel; combustion evaluation; household cookstove; testing conditions; emission factors; thermal performance

\section{Introduction}

More than three billion people rely on solid fuels such as biomass (wood, charcoal, agricultural residues, and animal dung) and coal as their primary sources of household energy all over the world [1]. Since poorly-designed stoves might harm human health and the atmosphere, many programs have been carried out to promote clean-burning household appliances [2,3].

Based on the needs of stove evaluations required by stove promotion, many testing methods were developed. However, with cooking habits and economic situations differing from one place to another, testing sequences vary greatly. For example, "Test Performance Method of Domestic Biofuel Cooking Stove" (Chinese agricultural standard, NY/T 2370-2013) [4] requires a certain mass of fuel with batch-load, while the International Workshop Agreement (IWA) referenced test method "Water Boiling Test (WBT) version 4.1.2" (now updated to version 4.2.3) [5] separates the test into three stages. 
The Indian Standard on Solid Biomass Chulha-Specification (BIS 13152) [6] is completely different from the Chinese national standards and the WBT version 4.2.3, with a testing cycle that requires pot-swapping. Besides different testing sequences, the testing operations and performance indicators of different testing methods also vary. For example, when considering pot lid operation, the Chinese testing method heats the pot with the lid on, but removes the lid when the water temperature reaches the boiling point; while WBT version 4.2.3 requires the lid to be off throughout the test. The ending points are also different [7].

With the development of the global stove market, the need for results from different testing methods that are comparable with each other becomes quite important. Many laboratories tested stoves based on the WBT version 4.2.3 method [8,9], but serious concerns have been raised due to some technical errors in the method [10]. Research studies have been conducted on different test conditions, but most of them focused on theoretical comparisons [11,12]. Some research studies have tried to compare the results from different testing methods. Pooja et al. [13] found that India's testing method and the WBT version 4.2.3 reported similar thermal performances but different emission performances, while Chen et al. [14] concluded that the Chinese testing method reported higher efficiencies and lower emissions than the WBT version 4.2.3. At the same time, some studies evaluated the influences of single operations, such as ventilation and fuel moisture. Raman et al. [15] showed that, for certain areas and test methods, forced draft stoves have the best performance, and MacCarty et al. [8] indicated that pollutants emitted from the forced draft stove are lowered by $90 \%$ compared with traditional stoves.

Contextual tests are still not as well developed nor as widely accepted [16], and no systematic multi-replicate testing data is reported for comparisons of different testing operations and indicators. This study designed an orthogonal test to investigate the influence of different test operations on thermal and emission performances. Differences between the testing results for two different based indicators were also analyzed.

\section{Materials and Methods}

\subsection{Biomass Fuel}

The fuel was in the form of commercial cylindrical wood pellets with the average dimension being $0.8 \mathrm{~cm}$ in diameter and $3 \mathrm{~cm}$ in length. The raw materials were pine and oak sawdust from a nearby furniture factory in Yantai, Shandong Province, China. The average moisture content of the fuel was $6.38 \%$ (wet base), and pellets were well stored to ensure a uniform moisture level during the tests. The dry basis lower heating value (LHV) of the fuel was $16.8 \mathrm{MJ} / \mathrm{kg}$, measured by oxygen bomb calorimeter. The elemental composition of the fuel was analyzed using a trace element analyzer (see Table 1). Solid alcohol was used for ignition, which rendered the starting phase convenient and reproducible. The total energy in the ignition fuel was included in the thermal efficiency calculation. All the fuel and kindling were added before ignition, according to the manufacturer's instructions.

Table 1. Ultimate and proximate analyses of the fuel.

\begin{tabular}{cccc}
\hline Ultimate Analysis (Dry Base) & $\%$ & Proximate Analysis (Wet Base) & $\%$ \\
\hline Carbon & 46.70 & Ash & 2.43 \\
Hydrogen & 6.70 & Volatile matter & 74.22 \\
Nitrogen & 1.31 & Fixed carbon & 16.97 \\
Sulfur & 0.20 & Moisture & 6.38 \\
\hline
\end{tabular}

\subsection{Stove and Pot}

A Chinses top-lit up-draft (TLUD) biomass semi-gasifier cooking stove was used in the study. Unlike the small cooking stoves in other research studies, it had a heavy mass and a chimney (see Figure 1). The heavy mass of the insulation material, which was mainly mud bricks between the inner and outside walls, stored much energy and cooled very slowly during the ending phase. 
The secondary air, forced or unforced by a fan, entered a preheating channel and emerged at the top of the combustion chamber. This was quite suitable for biomass combustion because biomass had a high level of volatile components. The stove was a batch loaded stove capable of holding a maximum of three kilograms of commercial cylindrical wood pellets per batch. This lasted for about two hours, which is adequate for most cooking tasks in China. The fuel was ignited on the top and went through three stages of burning, including a dehydrating phase, a pyrolysis and gas combustion phase, and a char burning phase. Hot gases moved into the top portion of the stove, where a large flame space and fire-blocking ring provided adequate flame residence time and enough surface area for efficient heat exchange to the pot. A 26- $\mathrm{cm}$ diameter and 9-liter stainless steel pot was used to test the cooking ability. A thermocouple was placed through the hole of the pot lid and remained $3 \mathrm{~cm}$ above the bottom of the pot to measure water temperature.
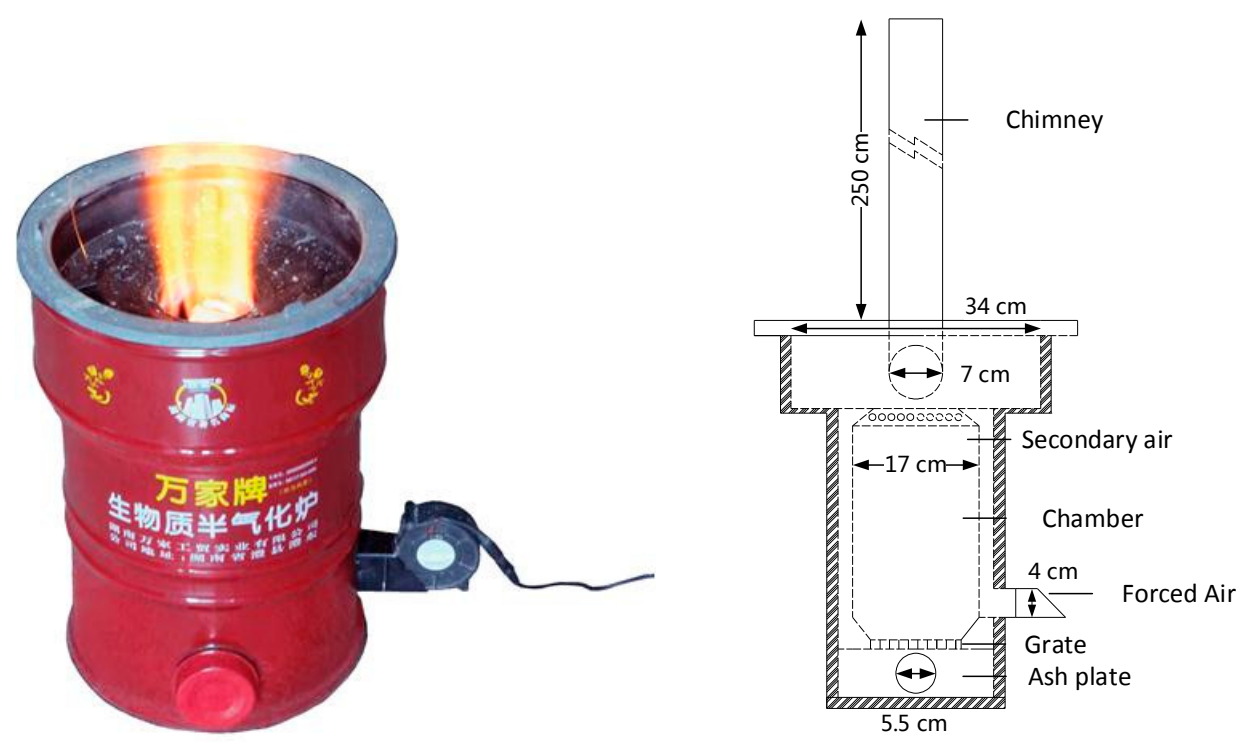

Figure 1. The stove and structure used in the current study.

\subsection{Emission Measurement System}

The emissions of the stoves were measured using an Emission Monitoring System (see Figure 2). The stove + pot in China was a sealed system in which the emissions from the stove can only go into the chimney and release outside the room (with leakage not being considered). A sample of the gas was drawn into a dilution tunnel which was mixed and diluted with particle-free air from an air compressor. At the end of the dilution tunnel, the well-mixed diluted gas went into a gas analyzer for $\mathrm{CO}$ and $\mathrm{CO}_{2}$ by non-dispersive infra-red (NDIR) sensors. Total suspended particulate (TSP) collectors collected all the particle matters (PMs) using quartz filters. Additionally, PM size distribution measurements were taken using an eight-grade impactor with quartz filters. All sensors were calibrated prior to conducting measurements. Filters were conditioned in a humidity controlled environment for $24 \mathrm{~h}$, and then weighed at $25{ }^{\circ} \mathrm{C}$ and $50 \%$ relative humidity. The dilution level of the sample was calculated using the formula below.

$$
\text { Dilution rate }=\frac{\mathrm{A}+\mathrm{B}+\mathrm{TSP} 1+\mathrm{TSP} 2}{\mathrm{~A}+\mathrm{B}+\mathrm{TSP} 1+\mathrm{TSP} 2-\text { Air compressor }}
$$

where "A" was the constant flow rate for impactor (in this system was $28.3 \mathrm{~L} / \mathrm{min}$ ), "B" was the constant flow rate for the gas analyzer (in this system was $1.3 \mathrm{~L} / \mathrm{min}$ ), and "TSP1," "TSP2," and "Air compressor" referred to different flow rate settings of the three parts respectively, as they would change due to different test conditions. 
For gas emissions, the mass of each gas was calculated by the carbon mass balance method, including measuring the fuel mass (with $0.1 \mathrm{~g}$ resolution), ash mass (with $0.1 \mathrm{~g}$ resolution), and gas concentration (with $1 \mathrm{ppm}$ resolution) as the inputs. For particles, the weight of the filter was measured using an electronic balance with a resolution of $0.01 \mathrm{mg}$.

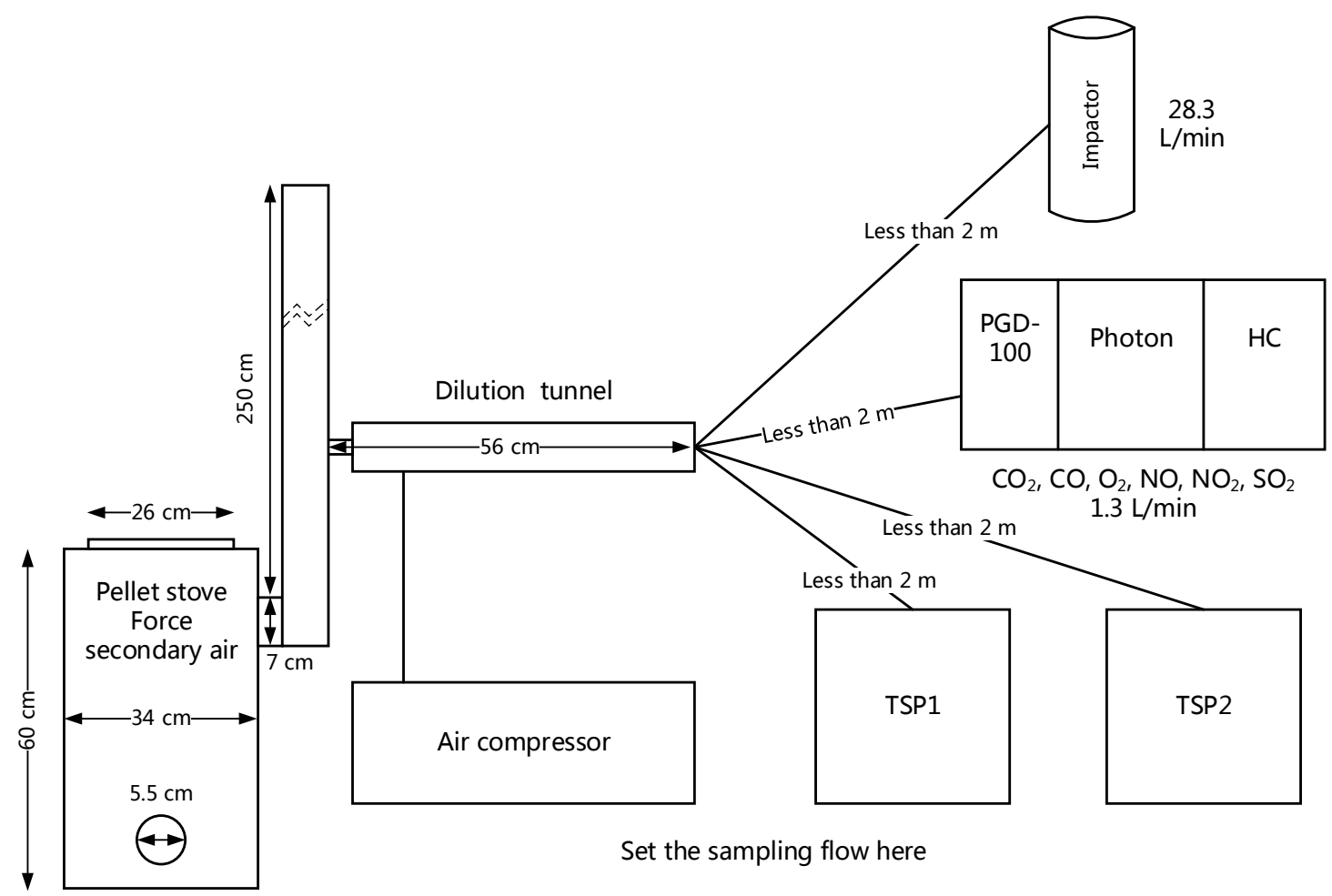

Figure 2. The testing system, including combustion, dilution and data collecting system. The impactor is used for eight-grade of particle size distribution, while two TSP1 and TSP2 are used to test total suspended particulate.

\subsection{Testing Conditions Set Up}

To design the test conditions, different operations required by the four widely used test methods were analyzed. The methods were the Chinese agricultural standard (NY/T 2369-2013, General technical specification of domestic biofuel cooking stove) [17], the Indian method BIS 13152 [6], the WBT version 4.2.3 method [5], and the Heterogeneous Testing Procedure for Thermal Performance and Trace Gas Emissions (HTP, SeTAR Center version) [18]. The main operational differences were listed in SI Table S1. There were certain requirements for pot sizes, water mass, fuel mass, lid operations, ending point operations, and fuel adding operations in these methods. The initial water mass was $7 \mathrm{~kg}$, since the maximum capacity of the pot was $9 \mathrm{~L}$. The lid operations varied from one method to another, with most of them heating the water when the lid was on. There were recommended fuel mass loadings according to the fire power of the stove, and it was observed that the fuel mass loadings significantly affected the results [19]. The chamber heights and ventilation rates were not requested by the listed test methods, but also had a significant influence on performance [20]. The test ending point operations were the most dissimilar, but little had been reported about this in the literature [11,12]. Combined with the actual stove design, a four-factor, three-level orthogonal test was designed to evaluate the stove performance under a range of conditions (see Table 2). 
Table 2. The factors of the experiments design.

\begin{tabular}{ccccc}
\hline Stove & Pot Size & Water Mass & Fuel & Lid Operation \\
\hline $\begin{array}{c}\text { Biomass } \\
\text { semi-gasified } \\
\text { cookstove with } \\
\text { forced second air }\end{array}$ & $26 \mathrm{~cm}$ & $7 \mathrm{~kg}$ & $\begin{array}{c}\text { Biomass pellet fuel, } \\
\text { normally } \varphi 0.8 \mathrm{~cm} \times 3 \mathrm{~cm}\end{array}$ & $\begin{array}{c}\text { Lid on, if the test reaching boiling } \\
\text { point, remove the lid for boiling }\end{array}$ \\
\hline Factors & $\begin{array}{c}\text { A Fuel } \\
\text { Masses }\end{array}$ & $\begin{array}{c}\text { B Chamber } \\
\text { Heights }\end{array}$ & C Air Conditions & D Operations (Ending Points) \\
\hline Level 1 & $1 \mathrm{~kg}$ & $39 \mathrm{~cm}$ & $\begin{array}{c}\text { With force draft } \\
\text { secondary air }\end{array}$ & $\begin{array}{l}\text { Do not change the pot, ends when it } \\
\text { reaches } 5{ }^{\circ} \mathrm{C} \text { below the boiling point }\end{array}$ \\
\hline Level 2 & $2 \mathrm{~kg}$ & $36 \mathrm{~cm}$ & $\begin{array}{c}\text { With nature draft } \\
\text { secondary air }\end{array}$ & $\begin{array}{l}\text { Change the pot when it reaches } 80^{\circ} \mathrm{C}, \\
\text { ends when the heating rate is below } \\
2{ }^{\circ} \mathrm{C} / \text { min }\end{array}$ \\
\hline Level 3 & $1.5 \mathrm{~kg}$ & $33 \mathrm{~cm}$ & $\begin{array}{l}\text { Change the pot when it reaches the } \\
5{ }^{\circ} \mathrm{C} \text { below the boiling point, ends } \\
\text { when the heating rate is below } \\
2{ }^{\circ} \mathrm{C} / \text { min }\end{array}$ \\
\hline
\end{tabular}

\subsection{Emission Indicators}

Different requirements of the tests are shown in SI Table S2. The Ringelmann blackness method used in the Chinese agricultural standard (NY/T 2370-2013) was a visual method that used statistical data to determine the smoke emission levels. This method not only required the testers to be professional, but also required good testing conditions, which is more suitable for testing the stable emissions from industrial boilers [21]. For the lab test, TSP was used instead of the Ringelmann blackness in this study. Three out of four methods gave numbers for $\mathrm{CO}_{2}$, because they could be used to characterize the combustion conditions [22]. However, since $\mathrm{CO}_{2}$ is the product of complete combustion, and not one of the pollutants, it was not used in this study. When comparing the indicators under different conditions, emission factors (EFs) could be used to make the results more comparable. However, there are many different EFs, such as the fuel mass-based (used in WBT version 4.2.3) or the useful energy-based (used in Indian method); these differences would result in different test results. The EFs were defined as follows:

$$
\begin{gathered}
\text { Emission factors (Useful energy based })=\frac{\text { Emission mass }}{\text { Useful energy }} \\
\text { Emission factors (Fuel mass based })=\frac{\text { Emission mass }}{\text { Fuel mass }}
\end{gathered}
$$

The differences of fuel mass-based $(\mathrm{g} / \mathrm{kg})$ and useful energy-based $(\mathrm{g} / \mathrm{MJ})$ emission factors were also analyzed in this paper. Based on the resolution and accuracy of the instruments, the thermal efficiency and CO EFs were reported to one decimal place (by g/ $\mathrm{kg}$ or $\mathrm{g} / \mathrm{MJ}$ ), and the PM EFs were reported with three decimals (by g/ $\mathrm{kg}$ or $\mathrm{mg} / \mathrm{MJ}$ ).

\subsection{Quality Control}

The carbon balance method was used to calculate the emission factors and control the data quality. The basic theory of the carbon balance is found in the following equation [23].

$$
\mathrm{C}_{f}-\mathrm{C}_{a}=\mathrm{C}_{\mathrm{CO}_{2}}+\mathrm{C}_{\mathrm{CO}}+\mathrm{C}_{\mathrm{CH}_{4}}+\mathrm{C}_{\mathrm{TNMHC}}+\mathrm{C}_{\mathrm{TSP}}
$$

wherein:

$C_{f}=$ carbon mass in the fuel, $\mathrm{g}$; 
$C_{a}=$ carbon mass in the ash, $\mathrm{g}$;

$\mathrm{C}_{\mathrm{CO}_{2}}=$ carbon mass in the $\mathrm{CO}_{2}$, g;

$\mathrm{C}_{\mathrm{CO}}=$ carbon mass in the $\mathrm{CO}, \mathrm{g}$;

$\mathrm{C}_{\mathrm{CH}_{4}}=$ carbon mass in the $\mathrm{CH}_{4}, \mathrm{~g}$;

$C_{T N M H C}=$ carbon mass in the total non-methane hydrocarbon, $\mathrm{g}$;

$C_{T S P}=$ carbon mass in the TSP, $\mathrm{g}$.

The advantage of using a carbon balance method was that it did not necessitate measuring the flow rate of the gas; it would therefore be relatively easier to obtain the raw data, since the combustion status of small stoves keeps changing. In contrast, the disadvantage of this method was that it only reported average results.

The stove was tested at least three times to report a coefficient of variation (COV), and tests with a COV greater than 0.2 for thermal efficiency and fire power would be repeated more often. All data were processed by Statistical Product and Service Solutions (SPSS version 20, Cary, NC, USA). Analysis of variance (ANOVA) was applied in the analysis. The significance level of the statistical analysis was $\mathrm{p}=0.05$ unless indicated otherwise.

\section{Results}

The thermal performance of the stove was illustrated in Table 3 and Figure 3, which presented the overall thermal efficiency, fuel mass-based $\mathrm{CO}$ emission factor (CO EF), useful energy-based CO EF, fuel mass-based particle matter (PM EF), and useful energy-based PM EF. Table 4 showed the significant level of different indicators.

Table 3. Results of orthogonal tests.

\begin{tabular}{ccccccc}
\hline No. & $\begin{array}{c}\text { Conditions } \\
\text { A/B/C/D }\end{array}$ & $\begin{array}{c}\text { Thermal } \\
\text { Efficiency } \%\end{array}$ & $\begin{array}{c}\text { CO EF (Fuel } \\
\text { Mass-Based) g/kg }\end{array}$ & $\begin{array}{c}\text { CO EF (Useful } \\
\text { Energy-Based) g/MJ }\end{array}$ & $\begin{array}{c}\text { PM EF (Fuel } \\
\text { Mass-Based) g/kg }\end{array}$ & $\begin{array}{c}\text { PM EF (Useful } \\
\text { Energy-Based) } \mathbf{m g} / \text { MJ }\end{array}$ \\
\hline 1 & $1 / 1 / 1 / 1$ & 19.6 & 111.3 & 34.1 & 0.037 & 11.6 \\
2 & $1 / 2 / 2 / 2$ & 12.6 & 201.1 & 95.9 & 0.155 & 75.3 \\
3 & $1 / 3 / 3 / 3$ & 22.3 & 75.6 & 22.0 & 0.018 & 0.021 \\
4 & $2 / 1 / 2 / 3$ & 13.6 & 189.2 & 84.2 & 0.003 & 0.014 \\
5 & $2 / 2 / 3 / 1$ & 23.7 & 55.1 & 13.9 & 0.014 & 0.8 \\
6 & $2 / 3 / 1 / 2$ & 25.5 & 43.1 & 36.0 & 0.011 & 2.0 \\
7 & $3 / 1 / 3 / 2$ & 23.7 & 128.5 & 23.0 & 0.050 & 2.9 \\
8 & $3 / 2 / 1 / 3$ & 26.0 & 87.2 & 82.9 & & \\
9 & $3 / 3 / 2 / 1$ & 14.0 & 193.8 & & & \\
\hline
\end{tabular}

Table 4. Significant influences of different indicators.

\begin{tabular}{cccccc}
\hline Source & $\begin{array}{c}\text { Thermal } \\
\text { Efficiency }\end{array}$ & $\begin{array}{c}\text { CO EF (Fuel } \\
\text { Mass-Based) }\end{array}$ & $\begin{array}{c}\text { CO EF (Useful } \\
\text { Energy-Based) }\end{array}$ & $\begin{array}{c}\text { PM EF (Fuel } \\
\text { Mass-Based) }\end{array}$ & $\begin{array}{c}\text { PM EF (Useful } \\
\text { Energy-Based) }\end{array}$ \\
\hline A Fuel mass & 0.007 & 0.020 & 0.058 & 0.001 & 0.001 \\
B Chamber heights & 0.018 & 0.032 & 0.112 & 0.036 & 0.010 \\
C Air condition & 0.000 & 0.000 & 0.000 & 0.000 & 0.000 \\
D Operation & 0.620 & 0.885 & 0.734 & 0.006 & 0.004 \\
\hline
\end{tabular}

Different factors had the same influences on thermal efficiencies and CO EFs when expressed in fuel mass-based form. This was because the $\mathrm{CO}$ was a product of incomplete combustion and was also being used to calculate the combustion efficiency. There was a negative relationship between thermal efficiencies and CO EFs in this test with $\mathrm{R}^{2}=0.838$, which means the less CO generated, the higher the combustion efficiency if other conditions remain the same [24].

Values of thermal efficiency within $12.6 \%$ to $26.0 \%$ were comparable with other studies [25]. Fuel mass, chamber heights, and ventilation had significant effects on thermal efficiencies. However, the operations (ending points) did not. The ending point directly influenced the fire power, such as 
with the temperature of water in the pot dropping to $5^{\circ} \mathrm{C}$ below the boiling point. The Chinese testing method had a low power phase at the end [14]. Although some investigations showed that the cooking efficiency had a relationship with fire power, and at certain powers are at the highest efficiency [26], the power changing during a batch-load testing sequence (normally "low-high-low" [27]) might eliminate this trend. The best condition for thermal efficiency $(26.0 \%)$ was fuel mass at $1.5 \mathrm{~kg}$ and chamber height of $36 \mathrm{~cm}$ with natural secondary air. The best condition for CO EF (fuel mass-based $43.1 \mathrm{~g} / \mathrm{kg}$ ) was fuel mass at $2 \mathrm{~kg}$ and chamber height at $33 \mathrm{~cm}$, with forced secondary air.

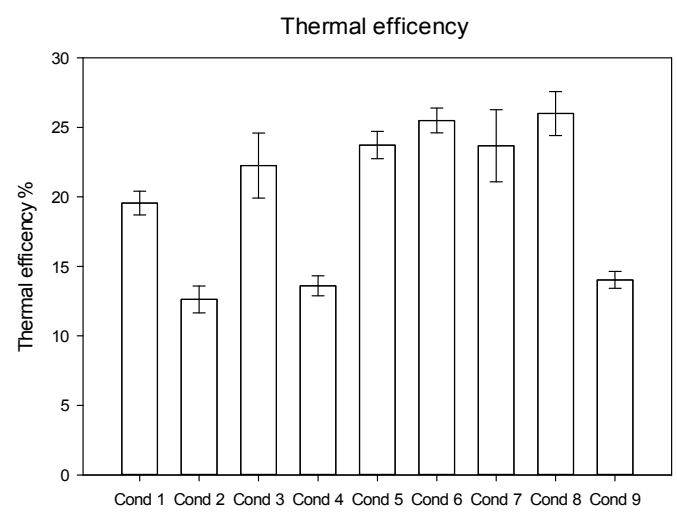

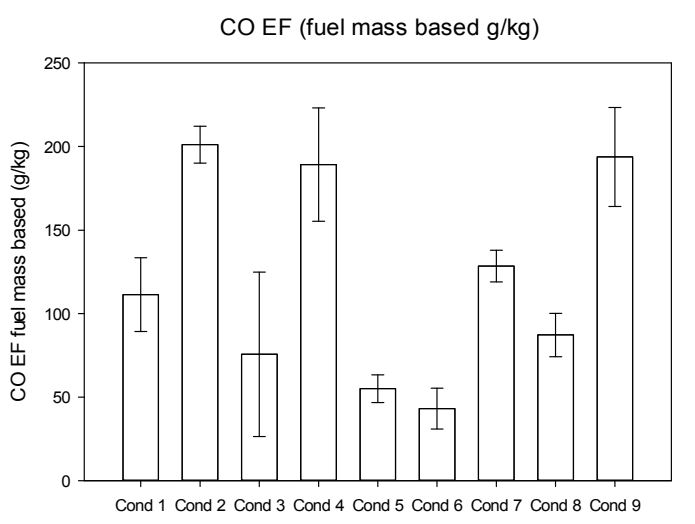

(b)

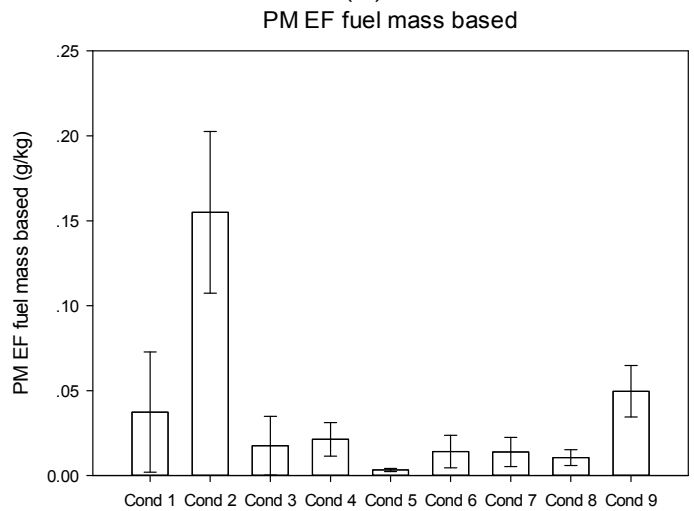

(d)

(a)

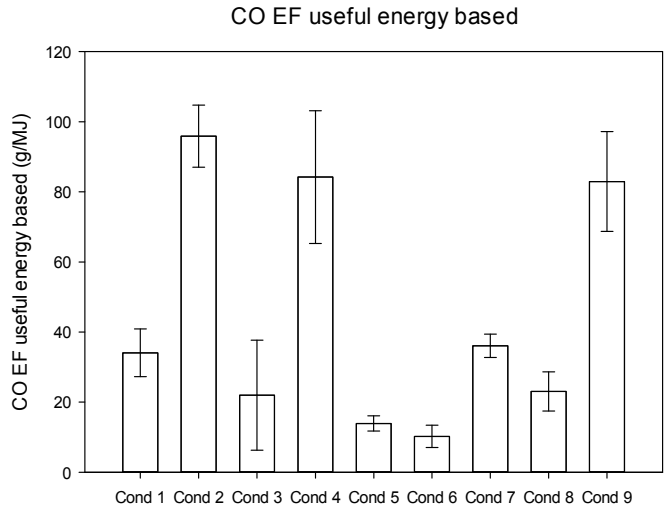

(c)

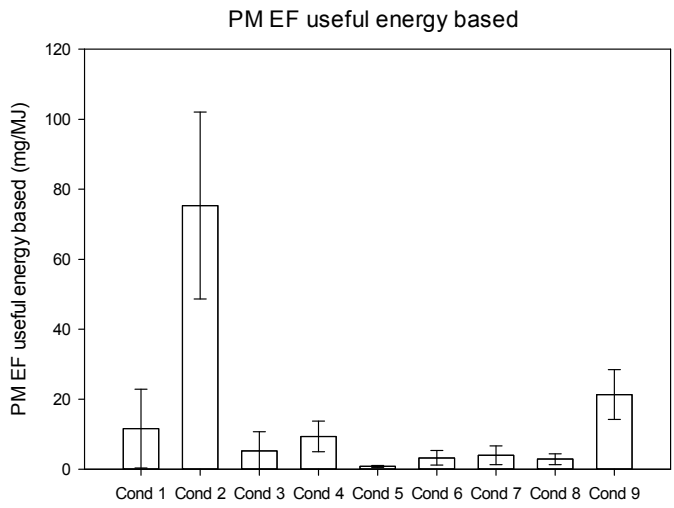

(e)

Figure 3. The average performance indicators of different conditions ((a) thermal efficacy; (b) fuel mass-based CO EF; (c) useful energy-based CO EF; (d) fuel mass-based PM EF; (e) useful energy-based PM EF) Cond 1 to Cond 9 were the same conditions as shown in Table 3.

Normally, the system's thermal efficiency was the product of combustion efficiency and heat transfer efficiency, and the heat transfer efficiency was closely related to the "stove + fuel" combination. 
From Figure 3a,b, it may be seen that the thermal efficiencies with forced secondary air (with average $23.7 \%$ ) were much greater than those using only natural secondary air (with average $13.4 \%$ ). It should be noticed that the $\mathrm{CO}$ emissions from biomass combustion mainly relied on three factors: gas temperature, oxygen concentration and fuel-oxygen mixing. More oxygen would result in either a reduced gas temperature (possibly resulting in a higher $\mathrm{CO} \mathrm{EF}$ ) or additional residence time for a well-mixed combustion (possibly resulting in a lower $\mathrm{CO}$ EF). A stove should have a better design to provide just enough air. The best combustion conditions for this stove were with forced secondary air [28].

It was important to note that, with this testing sequence, the CO EFs (whether useful energy-based or fuel mass-based) were much higher than the test results reported by WBT version 4.2.3 [5]. The CO EF of this test was within 50-200 g/ kg and was comparable with Shen et al. [29], who used raw corn straw on the Chinese stove. Sevault et al. even showed $174.2-269.7 \mathrm{~g} / \mathrm{kg}$ for wood stove using charcoal [30]. On the other hand, the number of CO EFs using WBT version 4.2.3 were usually in the range of $10-50 \mathrm{~g} / \mathrm{kg}[8,23,31]$. This was because the Chinese testing sequence included a burnout phase at the end of the test when the remaining fuel was mainly charcoal [32]. Hot charcoal burning usually needed more air and a better air-fuel mix. The absence of this condition would result in a high level of CO (see Figure 4). The WBT version 4.2.3 ended when the water temperature reached boiling point, when the fuel was still burning and did not reach the burnout phase. It was suggested to include the burnout phase in all tests. This was because, even though the user may have already finished the cooking task, the stove was still placed in the room. With ash not being removed, the emissions of the stove still go into the room (or outside if the stove had a chimney). Although most of the Chinese semi-gasifier stoves were equipped with chimneys to lower the indoor emissions, they still contribute to the outdoor air pollution.

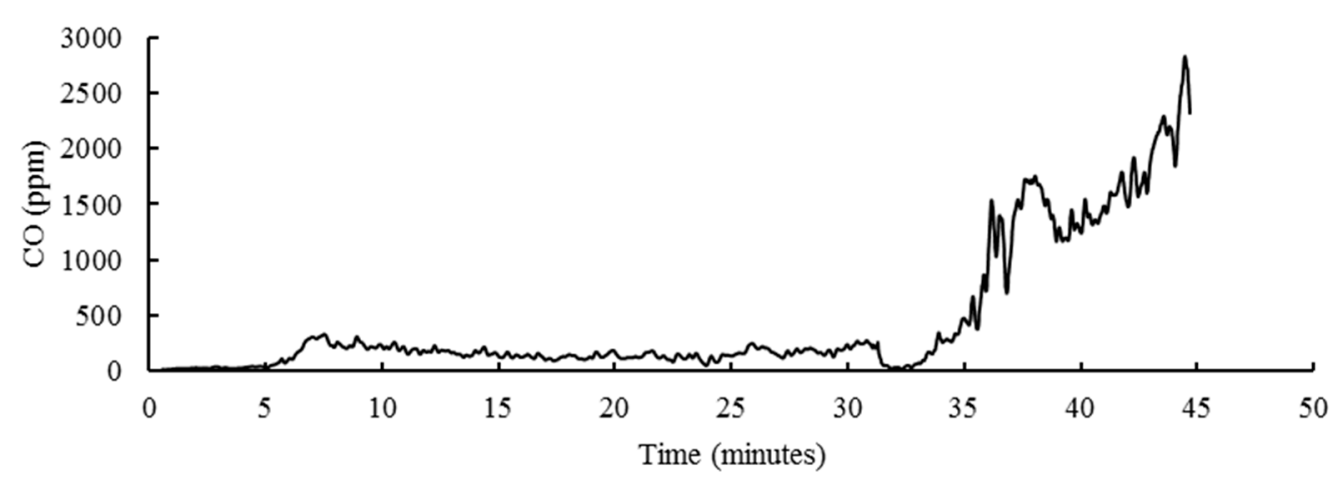

Figure 4. The typical CO emission of the Chinese burning cycle.

For PM EFs, no matter whether it is expressed in useful energy-based or fuel mass-based form, all four factors had significant effects on the outputs. The best conditions for PM EF $(0.003 \mathrm{~g} / \mathrm{kg})$ were: a fuel mass of $2.0 \mathrm{~kg}$, a chamber height of $36 \mathrm{~cm}$ with forced secondary air, and without pot change. This result was similar to the research of Chen et al. [14]. The normal PM EF of this test was around $10-150 \mathrm{mg} / \mathrm{kg}$, and the number of WBT version 4.2 .3 was normally $10-300 \mathrm{mg} / \mathrm{kg}$ based on different test conditions [33-35]; however, Deng et al. [36] reported high numbers with 2.5-3.5 g/ kg. The reported PM EF numbers were similar to the existing literature because the PM was mainly generated during ignition, and all the testing sequences of current testing methods included the ignition. The PM generated at the burnout phase was relatively small and would not contribute significantly to the total [37]. Furthermore, the PM EF with forced air (fuel mass-based average $0.016 \mathrm{~g} / \mathrm{kg}$ ) was lower than other stoves without it (fuel mass-based average $0.075 \mathrm{~g} / \mathrm{kg}$ ). It was suggested that Chinese stove designers should pay more attention to $\mathrm{CO}$ emissions during their research [16]. 
It should be noted that, because of the different emission factor bases used, the results might change. In this case study, the fuel mass and chamber heights had significant influences on the CO emission when using fuel mass-based emission factors, but had no significant influences when using useful energy-based emission factors. For a useful energy-based emission factor, the heat transfer process from fire to pot was taken into account, compared with the only fuel mass-based emission factor. For any given region, the useful energy-based emission factors linked the test results with the local cooking tasks and habits, which made reporting more realistic and representative. Based on the evaluation of this stove, it was very important to have those indicators discussed when creating an international standard that can serve as a decision-making tool, and would influence international trade.

The carbon balance method was used as a quick data quality check by summing all the carbons collected by the instruments and dividing them by the total carbon input. The results of the data quality check were within $75 \%-99 \%$, which meant that less than $25 \%$ of carbon was not captured.

Combining the results of thermal efficiency and the CO/PM EFs, the recommended conditions for this stove to give optimal performance were: a fuel mass of $2.0 \mathrm{~kg}$, a chamber height of $36 \mathrm{~cm}$ with forced secondary air, and without pot change. All four factors had significant influences on some specific indicators, which meant all these factors should be carefully evaluated when forming standard testing procedures. This study only focused on the technical "results-oriented" influences. Therefore, more complex and systemic social investigations may be needed to describe stove operations that reflect local customs and cooking habits.

\section{Conclusions}

The effects of different operations during the performance evaluation of a semi-gasifier cooking stove were analyzed in this study. The results showed that using forced secondary air and a higher fuel load (2.0 kg) gave better performance on both thermal efficiency (average 20.9\%) and CO EFs (average $95.8 \mathrm{~g} / \mathrm{kg}$ ). The ending points did not have a significant effect on thermal efficiencies and CO EFs, but had significant effects on PM EFs. Testing without pot changing produced lower PM EFs (average $0.030 \mathrm{~g} / \mathrm{kg}$ ). For chamber heights, a middle gap (chamber height $36 \mathrm{~cm}$ ) gave better thermal performance (average 20.8\%) and worse PM EFs (average $0.056 \mathrm{~g} / \mathrm{kg}$ ) than the big gap (chamber in height of $39 \mathrm{~cm}$, with average thermal efficiency of $18.9 \%$ and average PM EFs of $0.024 \mathrm{~g} / \mathrm{kg}$ ). The large differences between performance indicators resulting from the different burn cycles appeared most prominently when comparing the CO EFs. It was suggested that reporting emission factors by different bases should be discussed when forming international standards. It was better to use a "useful energy-based EF" than a fuel mass based one, because this indicator considered the stove and pot as a single system, and was therefore, more representative. This study provided useful information on the vital role of operations/indicators/calculations when reporting the performance of cooking stoves.

Supplementary Materials: The following are available online at www.mdpi.com/1996-1073/11/5/1131/s1, Table S1: The main operational differences between test methods; Table S2: The outputs of the test methods.

Author Contributions: Y.Z., Z.Z. and Y.Z. conceived and designed the experiments; Y.Z. and K.Z. performed the experiments, analyzed the data and wrote the paper; K.Z. and Y.Z. conducted the proof-reading work; Y.Z. and R.D. contributed grants/reagents/materials/analysis tools.

Acknowledgments: The research was supported in part by Agricultural Product Quality Inspection Bureau, Ministry of Agriculture of Rural Affairs, China, Agricultural Industry Standard Development Project "Determination method of major atomosphere pollutants from rural household stoves" (No. 181721301092371112); the bilateral China-South Africa MoST-NRF joint project "Development of Scientifically Robust and Culturally Appropriate Metrics and Protocols for Evaluating Clean (Combustion) Cookstoves", sponsored by Ministry of Science and Technology, China; the World Bank Group Project for "Clean and Efficient Heating Stove South-South Knowledge Exchange" (No. 7182688); the Project for "China-Ghana Renewable Energy Technology Transfer Cooperation" from the Administrative Center for China's Agenda 21. The work was carried out by the Key Laboratory of Clean Production and Utilization of Renewable Energy, Ministry of Agriculture and Rural Affairs, China Agricultural University; National Center for International Research of BioEnergy Science and Technology, Ministry of Science and Technology, China Agriculture University; and Beijing Municipal Key Discipline of Biomass Engineering. 
Conflicts of Interest: The authors declare no conflict of interest.

\section{References}

1. Anenberg, S.C.; Balakrishnan, K.; Jetter, J.; Masera, O.; Mehta, S.; Moss, J.; Ramanathan, V. Cleaner cooking solutions to achieve health, climate, and economic cobenefits. Environ. Sci. Technol. 2013, 47, 3944-3952. [CrossRef] [PubMed]

2. Cordes, L. Igniting Change: A Strategy for Universal Adoption of Clean Cookstoves and Fuels; Global Alliance for Clean Cookstoves (GACC): Washington, DC, USA, 2011.

3. Venkataraman, C.; Sagar, A.; Habib, G.; Lam, N.; Smith, K. The Indian national initiative for advanced biomass cookstoves: The benefits of clean combustion. Energy Sustain. Dev. 2010, 14, 63-72. [CrossRef]

4. Ministry of Agriculture. Test Performance Method of Domestic Biofuel Cooking Stove (NY/T 2370-2013); Ministry of Agriculture: Beijing, China, 2013.

5. Global Alliance for Clean Cookstoves. The Water Boiling Test (WBT V4.2.3); Global Alliance for Clean Cookstoves: Washington, DC, USA, 2014.

6. Bureau of Indian Standards. Indian Standard on Portable Solid Biomass Chulha (BIS 13152 (Part 1): 2013); Bureau of Indian Standards: New Delhi, India, 2013.

7. Lombardi, F.; Riva, F.; Bonamini, G.; Barbieri, J.; Colombo, E. Laboratory protocols for testing of Improved Cooking Stoves (ICSs): A review of state-of-the-art and further developments. Biomass Bioenergy 2017, 98, 321-335. [CrossRef]

8. MacCarty, N.; Still, D.; Ogle, D. Fuel use and emissions performance of fifty cooking stoves in the laboratory and related benchmarks of performance. Energy Sustain. Dev. 2010, 14, 161-171. [CrossRef]

9. Jetter, J.J.; Kariher, P. Solid-fuel household cook stoves: Characterization of performance and emissions. Biomass Bioenergy 2009, 33, 294-305. [CrossRef]

10. Zhang, Z.; Zhang, Y.; Zhou, Y.; Ahmad, R.; Pemberton-Pigott, C.; Annegarn, H.; Dong, R. Systematic and conceptual errors in standards and protocols for thermal performance of biomass stoves. Renew. Sustain. Energy Rev. 2016, 72, 1343-1354. [CrossRef]

11. Zhang, Y.; Pernberton-Piqott, C.; Zhang, Z.; Ding, H.; Zhou, Y.; Dong, R. Key differences of performance test protocols for household biomass cookstoves. In Proceedings of the 2014 Twenty-Second Domestic Use of Energy (DUE), Cape Town, South Africa, 1-2 April 2014.

12. Ding, H.Y.; Liu, J.X.; Zhang, Y.X.; Dong, R.J.; Pang, C.L. Key factors of thermal efficiency test protocols for household biomass cookstoves. Adv. Mater. Res. 2013, 724-725, 268-273. [CrossRef]

13. Arora, P.; Das, P.; Jain, S.; Kishore, V.V.N. A laboratory based comparative study of Indian biomass cookstove testing protocol and Water Boiling Test. Energy Sustain. Dev. 2014, 21, 81-88. [CrossRef]

14. Chen, Y.; Shen, G.; Su, S.; Du, W.; Huangfu, Y.; Liu, G.; Wang, X.; Xing, B.; Smith, K.R.; Tao, S. Efficiencies and pollutant emissions from forced-draft biomass-pellet semi-gasifier stoves: Comparison of International and Chinese water boiling test protocols. Energy Sustain. Dev. 2016, 32, 22-30. [CrossRef]

15. Raman, P.; Murali, J.; Sakthivadivel, D.; Vigneswaran, V. Performance evaluation of three types of forced draft cook stoves using fuel wood and coconut shell. Biomass Bioenergy 2013, 49, 333-340. [CrossRef]

16. Carter, E.M.; Shan, M.; Yang, X.; Li, J.; Baumgartner, J. Pollutant emissions and energy efficiency of Chinese gasifier cooking stoves and implications for future intervention studies. Environ. Sci. Technol. 2014, 48, 6461-6467. [CrossRef] [PubMed]

17. Ministry of Agriculture. General Technical Specification of Domestic Biofuel Cooking Stove (NY/T 2369-2013); Ministry of Agriculture: Beijing, China, 2013.

18. South Africa University of Johannesburg. The Heterogeneous Testing Procedure for Thermal Performance and Trace Gas Emissions (HTP); South Africa University of Johannesburg: Johannesburg, South Africa, 2012.

19. Birzer, C.; Medwell, P.; Wilkey, J.; West, T.; Higgins, M.; MacFarlane, G.; Read, M. An analysis of combustion from a top-lit up-draft (TLUD) cookstove. J. Hum. Eng. 2013, 2, 1-7.

20. Hou, S.-S.; Ko, Y.-C. Effects of heating height on flame appearance, temperature field and efficiency of an impinging laminar jet flame used in domestic gas stoves. Energy Convers. Manag. 2004, 45, 1583-1595. [CrossRef] 
21. Srinivasarao, R.; Krishna, K.M. Automatic control of soot and unburnt hydro carbons from flares in oil and gas industry. In Proceedings of the 2014 International Conference and Utility Exhibition on Green Energy for Sustainable Development (ICUE), Pattaya City, Thailand, 19-21 March 2014; pp. 1-5.

22. Nussbaumer, T.; Doberer, A.; Klippel, N.; Bühler, R.; Vock, W. Influence of ignition and operation type on particle emissions from residential wood combustion. In Proceedings of the 16th European Biomass Conference and Exhibition, Valencia, Austria, 2-6 June 2008; pp. 2-6.

23. Zhang, J.; Smith, K.; Ma, Y.; Ye, S.; Jiang, F.; Qi, W.; Liu, P.; Khalil, M.; Rasmussen, R.; Thorneloe, S. Greenhouse gases and other airborne pollutants from household stoves in China: A database for emission factors. Atmos. Environ. 2000, 34, 4537-4549. [CrossRef]

24. Nussbaumer, T. Combustion and co-combustion of biomass: Fundamentals, technologies, and primary measures for emission reduction. Energy Fuel 2003, 17, 1510-1521. [CrossRef]

25. Obeng, G.Y.; Mensah, E.; Ashiagbor, G.; Boahen, O.; Sweeney, D. Watching the Smoke Rise Up: Thermal Efficiency, Pollutant Emissions and Global Warming Impact of Three Biomass Cookstoves in Ghana. Energies 2017, 10, 641. [CrossRef]

26. Kandpal, J.B.; Maheshwari, R.C.; Kandpal, T.C. Release of air pollutants in indoor air: Comparison of traditional and metallic cookstoves. Renew. Energy 1994, 4, 833-837. [CrossRef]

27. Patel, S.; Leavey, A.; He, S.; Fang, J.; O’Malley, K.; Biswas, P. Characterization of gaseous and particulate pollutants from gasification-based improved cookstoves. Energy Sustain. Dev. 2016, 32, 130-139. [CrossRef]

28. Roy, M.M.; Dutta, A.; Corscadden, K. An experimental study of combustion and emissions of biomass pellets in a prototype pellet furnace. Appl. Energy 2013, 108, 298-307. [CrossRef]

29. Shen, G.; Yang, Y.; Wang, W.; Tao, S.; Zhu, C.; Min, Y.; Xue, M.; Ding, J.; Wang, B.; Wang, R. Emission factors of particulate matter and elemental carbon for crop residues and coals burned in typical household stoves in China. Environ. Sci. Technol. 2010, 44, 7157-7162. [CrossRef] [PubMed]

30. Sevault, A.; Khalil, R.A.; Enger, B.C.; Skreiberg, O.; Goile, F.; Wang, L.; Seljeskog, M.; Kempegowda, R. Performance Evaluation of a Modern Wood Stove Using Charcoal. Energy Procedia 2017, 142, 192-197. [CrossRef]

31. Venkataraman, C.; Rao, G.U.M. Emission factors of carbon monoxide and size-resolved aerosols from biofuel combustion. Environ. Sci. Technol. 2001, 35, 2100-2107. [CrossRef] [PubMed]

32. Kang, S.; Sim, B.; Kim, J. Volume and Mass Measurement of a Burning Wood Pellet by Image Processing. Energies 2017, 10, 603. [CrossRef]

33. Bäfver, L.S.; Leckner, B.; Tullin, C.; Berntsen, M. Particle emissions from pellets stoves and modern and old-type wood stoves. Biomass Bioenergy 2011, 35, 3648-3655. [CrossRef]

34. Shen, G.; Tao, S.; Wei, S.; Zhang, Y.; Wang, R.; Wang, B.; Li, W.; Shen, H.; Huang, Y.; Chen, Y. Reductions in emissions of carbonaceous particulate matter and polycyclic aromatic hydrocarbons from combustion of biomass pellets in comparison with raw fuel burning. Environ. Sci. Technol. 2012, 46, 6409-6416. [CrossRef] [PubMed]

35. Boman, C.; Pettersson, E.R.; Westerholm, R.; Boström, D.; Nordin, A. Stove performance and emission characteristics in residential wood log and pellet combustion, part 1: Pellet stoves. Energy Fuel 2011, 25, 307-314. [CrossRef]

36. Deng, L.; Torres, R.D.; Burford, M.; Whitlow, H.T.; Lehmann, J.; Fisher, M.E. Fuel sensitivity of biomass cookstove performance. Appl. Energy 2018, 215, 13-20. [CrossRef]

37. Miljevic, B.; Heringa, M.; Keller, A.; Meyer, N.; Good, J.; Lauber, A.; Decarlo, P.; Fairfull-Smith, K.; Nussbaumer, T.; Burtscher, H. Oxidative potential of logwood and pellet burning particles assessed by a novel profluorescent nitroxide probe. Environ. Sci. Technol. 2010, 44, 6601-6607. [CrossRef] [PubMed]

(C) 2018 by the authors. Licensee MDPI, Basel, Switzerland. This article is an open access article distributed under the terms and conditions of the Creative Commons Attribution (CC BY) license (http:/ / creativecommons.org/licenses/by/4.0/). 